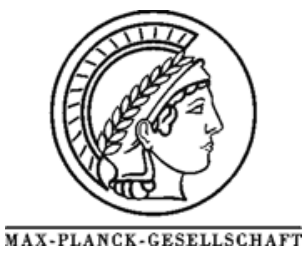

Microporous and Mesoporous Materials 95 (2006) 339-349

\title{
The mechanism for the controlled synthesis of highly dispersed vanadia supported on silica SBA-15
}

\author{
C. Hess*, U. Wild, R. Schlögl \\ Department of Inorganic Chemistry, Fritz-Haber-Institute of the MPG, Faradayweg 4-6, 14195 Berlin, Germany \\ *Corresponding author: e-mail hess@fhi-berlin.mpg.de,
}

Received 30 March 2006; received in revised form 6 June 2006; accepted 8 June 2006

Available online 20 July 2006

\begin{abstract}
The mechanism for the controlled synthesis of highly dispersed vanadia supported on mesoporous silica SBA-15 (VO $\left./ \mathrm{VB}_{\mathrm{SB}}-15\right)$ is elucidated using X-ray photoelectron spectroscopy (XPS), Raman and diffuse reflectance infrared Fourier-transform spectroscopy (DRIFTS). The synthesis consists of functionalization of SBA-15 using 3-aminopropyltrimethoxysilane (APTMS) followed by HCl treatment, anion exchange of decavanadate $\left(\mathrm{V}_{10} \mathrm{O}_{28}{ }^{6-}\right)$ and calcination to yield the final material. Spectroscopic analysis yields that APTMS is grafted onto the surface via hydroxyl groups. Under ambient conditions, protonated APTMS on SBA-15 is largely hydrolyzed and present in its bidentate and tridentate form. Detailed XPS analysis reveals a strong influence of surface water on the resulting structure of APTMS on SBA-15. Under dry conditions, the protonated APTMS molecules on SBA-15 adopt the monodentate and bidentate form. During the anion exchange reaction, decavanadate is incorporated intactly into the pores, without any changes in the structure of the organic framework. In the calcination step, decavanadate is decomposed and vanadia is anchored onto the surface of SBA-15 via silanol groups resulting in highly dispersed surface vanadia species, while the organic residues are fully removed from the pores of the silica matrix.
\end{abstract}

Keywords: Supported vanadium oxide; Vanadia; SBA-15; XPS; Vibrational spectroscopy

\section{Introduction}

Silica SBA-15 is a mesoporous molecular sieve, which possesses uniform hexagonal channels ranging from 5 to $30 \mathrm{~nm}$ and a very narrow pore-size distribution [1]. Its large internal surface area $\left(>800 \mathrm{~m}^{2} / \mathrm{g}\right)$ allows for the dispersion of a large number of catalytically active centers, whereas its thick framework walls $(3.1-6.4 \mathrm{~nm})$ provide high hydr thermal stability that exceeds those of the thinner-walled MCM-41 materials [1-3]. On account of its well-defined structure and variability of the pore diameter, SBA-15 is ideally suited as support material for the preparation of three-dimensional model catalysts. Furthermore, it opens the possibility to study catalysis on well-defined, spatially separated transition metal centers. Despite its great potential use for catalytic applications, there have been only few reports on the preparation and application of SBA-15 supported vanadium oxide catalysts [4-9].

Vanadium oxides supported on silica exhibit high activity and selectivity for a number of model oxidation reac- tions, such as the partial oxidation of methane [10,11], methanol oxidation to formaldehyde $[8,12-14]$, and the oxidative dehydrogenation of ethane to ethylene [15]. To understand the correlation between structural and catalytic properties of dispersed vanadia, various techniques including infrared [16-18a,18b], Raman [19-23], UV-visible $[16,17,20,24,25]$, solid-state ${ }^{51} \mathrm{~V}$ NMR [21], and X-ray absorption spectroscopy $[18,26]$ have been used. In several studies, XPS has been employed to study the dispersion and oxidation state of supported vanadia catalysts [27,28]. One of the main goals of heterogeneous catalysis is to establish structure-activity relationships. However, controlled synthesis of catalytic materials with active sites, which are uniform in composition and distribution, is still a challenge. A promising strategy to produce uniform active sites on the surface of an oxide support is based on grafting of an organometallic precursor species followed by its transformation into an active site by chemical reactions [29-31]. Recently, supported vanadia catalysts have been prepared based on grafting of a tailored single-source tri(alkoxy)siloxy precursor compound onto the surface of 
mesoporous silica followed by thermal decomposition of the precursor [29,32]. Employing spectroscopic techniques such as infrared, UV-Vis, Raman, NMR, and EXAFS, the formation of the adsorbed precursor and the final catalyst were characterized [32]. By using molecular designed dispersion (MDD) of $\mathrm{VO}(\mathrm{acac})_{2}$, highly dispersed $\mathrm{VO}_{\mathrm{x}}$ species have been grafted onto SBA-15 [6]. In this study, the structure of the adsorbed $\mathrm{VO}(\mathrm{acac})_{2}$ precursor and the final catalyst have been studied using FTIR, Raman spectroscopy and thermogravimetric analysis (TGA), respectively.

In a previous publication we have shown that highly dispersed vanadia supported on SBA-15 can be prepared by a novel grafting/anion exchange method, which consists of organofunctionalization of SBA-15 using APTMS, subsequent anion exchange of decavanadate into the pores of the silica matrix and thermolysis of the precursor material [33]. As the precursor is tightly held electrostatically within the channels in a prearranged geometry, this approach allows for a precise control of the amount of vanadium introduced into the material. Raman and diffuse reflectance UV-Vis spectroscopy under dehydrated conditions revealed the presence of different vanadia structures (monomers, polymers and crystals) as a function of vanadium loading (0-22 $w t \% \mathrm{~V})$. Therefore, by variation of the loading the structural properties of the resulting vanadia phase can be controlled.

The functionalization of silica using 3aminopropyltriethoxysilane (APTS), which largely resembles the first step of our procedure, has been studied extensively using various spectroscopic techniques such as infrared, solid-state NMR, TGA and XPS [34,35]. These studies have shown that the presence of surface water strongly influences the resulting structure of the adsorbed APTS [36]. Depending on the amount of water exposure during the modification stages of silica (pretreatment, reaction, curing), different structures were formed. Extensive exposure to water resulted in the formation of an aminopropyl-polysiloxane layer. In contrast, by application of dry conditions during all modification stages the hydrolysis of ethoxy groups could be prevented.

In this article we present a detailed spectroscopic characterization of the synthesis of highly dispersed vanadia supported on silica SBA-15. XPS as well as vibrational spectroscopies, i.e. DRIFTS and Raman, are used to elucidate the chemical composition and structure at the surface of silica SBA-15 after each modification stage. This allows us to propose a detailed mechanism for the formation of $\mathrm{VO}_{\mathrm{x}} / \mathrm{SBA}-15$ based on results from various spectroscopic techniques. Here, we focus on the synthesis of a $\mathrm{VO}_{\mathrm{x}} /$ SBA-15 catalyst with a loading of $2.7 \mathrm{wt} \% \mathrm{~V}$. This vanadium loading was chosen because it is well below loadings, at which formation of $\mathrm{V}_{2} \mathrm{O}_{5}$ crystals was observed (9 wt\% V) [33]. Recently, this material was shown to exhibit an excellent catalytic performance in methanol partial oxidation to formaldehyde and propane partial oxidation to acrylic acid [8,9].

\section{Experimental}

\subsection{Material preparation}

Silica SBA-15 was synthesized according to the literature [1]. The resulting white powder was calcined at $550{ }^{\circ} \mathrm{C}$ for $12 \mathrm{~h}$ to obtain the final product. Details of the catalyst preparation were described elsewhere [33]. Briefly, the functionalization of SBA-15 was achieved by stirring $2.5 \mathrm{~g} \mathrm{SBA}-15$ in $100 \mathrm{ml}$ of toluene at $65{ }^{\circ} \mathrm{C}$ [37]. To this suspension, $6.5 \mathrm{~g}$ 3-aminopropyltrimethoxysilane (APTMS) was added while stirring. After stirring for $12 \mathrm{~h}$, the contents was filtered and washed with toluene. This dry, white powder (APTMS-SBA-15) was stirred in $150 \mathrm{ml}$ $0.3 \mathrm{MHCl}$ for $12 \mathrm{~h}$. The contents was filtered again, washed with water and dried in air overnight. SBA-15 supported vanadia was synthesized using functionalized SBA-15 and butylammonium decavanadate, $\left[\mathrm{H}_{3} \mathrm{NC}_{4} \mathrm{H}_{9}\right]_{6} \mathrm{~V}_{10} \mathrm{O}_{28}$, (deca) as starting material [38]. For a $2.7 \mathrm{wt} \% \mathrm{~V}$ catalyst, $73 \mathrm{mg}$ of butylammonium decavanadate were added to a suspension of $1 \mathrm{~g}$ functionalized SBA-15 in $40 \mathrm{ml}$ water. The contents was stirred for $12 \mathrm{~h}$, filtered, washed with water and dried in air, yielding an orange powder (deca-SBA-15). The powder was calcined at $550{ }^{\circ} \mathrm{C}$ for $12 \mathrm{~h}$ to yield the final supported vanadia catalyst $\left(\mathrm{VO}_{\mathrm{x}} / \mathrm{SBA}-15\right)$.

\subsection{Physical characterization}

The actual composition of the sample was determined by atomic absorption after the samples were dissolved in HF solution. Surface areas of the prepared samples were measured by nitrogen adsorption/desorption isotherms using a Quantasorb surface area analyzer and standard multipoint BET analysis methods. The samples were pretreated overnight in a vacuum line. SBA-15 and $\mathrm{VO}_{\mathrm{x}} /$ SBA-15 were pretreated at $200{ }^{\circ} \mathrm{C}$, APTMS-SBA- 15 and deca-SBA- 15 at $85{ }^{\circ} \mathrm{C}$, respectively. The deca sample was pretreated overnight in helium at room temperature and measured on a Quantasorb Jr. The pore volume was dete mined from the adsorption branch of the $\mathrm{N}_{2}$ isotherm curve at the $\mathrm{P} / \mathrm{P}_{0}=0.95$ signal point. The pore-size distribution was determined from the desorption branch of the isotherm using the BJH method. Transmission electron microscopy (TEM) was performed using a Philips CM $200 \mathrm{LaB}_{6}$ at an acceleration voltage of $200 \mathrm{kV}$.

\subsection{X-ray photoelectron spectroscopy (XPS)}

The measurements were carried out using a modified LHS/SPECS EA200 MCD system equipped with a $\mathrm{Mg} \mathrm{\textrm {K } _ { \alpha }}$ source $(1253.6 \mathrm{eV}, 168 \mathrm{~W})$. Spectra were run in both lowresolution (retardation ratio 4) and high-resolution (pass energy $48 \mathrm{eV}$ ) modes. X-ray satellites were removed numerically. The binding energy scale of the system was calibrated using $\mathrm{Au} 4 \mathrm{f}_{7 / 2}=84.0 \mathrm{eV}$ and $\mathrm{Cu} 2 \mathrm{p}_{3 / 2}=932.67 \mathrm{eV}$ from foil samples. The powder samples were placed as is in a stainless steel sample holder with a $0.6 \mathrm{~mm}$ deep rectangular well covering an area of $(12 \times 8) \mathrm{mm}^{2}$. The base pres- 
sure of the ultra-high vacuum (UHV) chamber was $1 \times 10^{-}$

${ }^{10}$ mbar. The position of the sample holder in the analysis chamber could be well reproduced allowing a good comparison of absolute intensities of different samples. Unless noted differently the acquisition time was $260 \mathrm{~min}$. Charging of the powder samples was accounted for by setting the peak of the Si2p signal to $103.6 \mathrm{eV}$ [39].AShirley background was subtracted from all spectra. Then peak fitting with a 30/70 Gauss-Lorentz product function was performed. Atomic ratios were determined from the integral intensities of the signals, which were corrected by empirically derived sensitivity factors [40].

\subsection{Raman spectroscopy}

The Raman spectrometer (Kaiser Optical) was equipped with a Nd:YAG laser which was frequency doubled to $532 \mathrm{~nm}$. The laser was operated at a power level of $25 \mathrm{~mW}$ measured at the sample using a power meter (Coherent). The spectral resolution of the spectrometer was 5 $\mathrm{cm}^{-1}$. To minimize the effect of laser heating the samples $(\sim 50 \mathrm{mg})$ were pressed into pellets at $40 \mathrm{MPa}$ and rotated at $20 \mathrm{~Hz}$ within a rotary quartz Raman cell. Sampling times were between 100 and 200 s. All Raman spectra were recorded under ambient conditions unless stated otherwise. The Raman spectra of the dehydrated vanadia samples were recorded at room temperature after heating the samples in flowing air at $400{ }^{\circ} \mathrm{C}$ for $1 \mathrm{~h}$.

\subsection{Diffuse reflectance infrared Fourier- transform spectroscopy (DRIFTS)}

DRIFT spectra were recorded on a Bruker IFS 66 spectrometer, with $4 \mathrm{~cm}^{-1}$ spectral resolution, equipped with a Graseby Specac diffuse reflectance accessory, after diluting the samples with $90 \%$ of oven-dried $\mathrm{KBr}$. The sampling time was $1000 \mathrm{~s}$. All spectra were recorded under ambient conditions. Spectra were normalized by using the $1770-1940 \mathrm{~cm}-1 \mathrm{Si}-\mathrm{O}$ band as a reference.

\section{Results and discussion}

\subsection{Synthesis of $V O_{x} / S B A-15$}

Fig. 1 depicts XP survey spectra, which highlight important steps of the synthesis of $2.7 \mathrm{wt} \% \mathrm{~V} / \mathrm{SBA}-15$. Detailed highresolution XP spectra of the corresponding compounds will be discussed below. The atomic ratios of the detected elements, as obtained from the XPS analysis, as well as their BET surface area values are listed in Table 1. Parts (a) and (b) of Fig. 1 show the spectra of untreated SBA-15 and APTMS-SBA-15, which has been functionalized with APTMS and subsequently treated with $\mathrm{HCl}$. As indicated in Fig. 1, the spectrum of SBA-15 is characterized by Si2s, $\mathrm{Si} 2 \mathrm{p}$ and O1s peaks. The spectrum of APTMSSBA-15 exhibits peaks corresponding to $\mathrm{C} 1 \mathrm{~s}, \mathrm{~N} 1 \mathrm{~s}, \mathrm{Cl} 2 \mathrm{~s}$ and $\mathrm{Cl} 2 \mathrm{p}$, in addition to the SBA-15-related $\mathrm{Si}$ and $\mathrm{O}$ peaks. The N/C and $\mathrm{N} / \mathrm{Cl}$ ratios (see Table 1) suggest the presence of the ammonium salt of APTMS on the surface of SBA-15 (see discussion below). The Si2s and Si2p peaks of SBA-15 and APTMS-SBA-15 appear at the same binding energy, which indicates that $\mathrm{Si}$ from silane is indistinguishable from $\mathrm{Si}$ in SBA-15. Part (c) displays the X-ray photoelectron spectrum of butylammonium decavanadate (deca), which serves as vanadium precursor in the synthesis of $\mathrm{VO}_{\mathrm{x}} / \mathrm{SBA}-15$. The observed peaks correspond to O1s, V2p, C1s, and N1s. The values for the atomic ratios given in Table 1 confirm the presence of intact butylammonium decavanadate. However, the O/V ratio of 2.4 (expected: 2.8 ) indicates that the sample is slightly reduced (see di cussion below). Part (d) of Fig. 1 shows the spectrum of deca-SBA-15, which was obtained from APTMS-SBA-15 by anion exchange with decavanadate. The presence of the $V 2 p_{3 / 2}$ peak and the slight increase of the $\mathrm{O} 1 \mathrm{~s}$ intensity are indicative of the presence of decavanadate in the pores of the silica matrix.

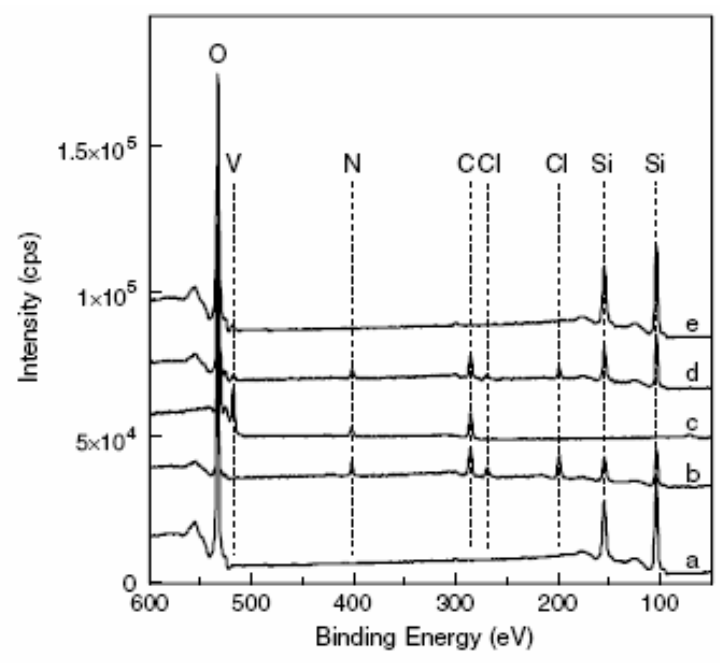

Figure 1: XP survey spectra of (a) SBA-15, (b) APTMSSBA-15, (c) deca, (d) deca-SBA-15, and (e) $2.7 \mathrm{wt} \%$ V/SBA-15. The spectra are offset for clarity.

Table 1: BET results and atomic ratios (\%) of the detected elements as obtained from the XPS analysis

\begin{tabular}{|c|c|c|c|c|c|c|c|c|}
\hline & $\mathrm{Na} 1 \mathrm{~s}$ & O ls & $\mathrm{V} 2 \mathrm{p}_{3 / 2}$ & N1s & $\mathrm{C} 1 \mathrm{~s}$ & $\mathrm{Cl}_{2} \mathrm{p}$ & Si2p & $\begin{array}{l}S_{\text {BET }} \\
\left(\mathrm{m}^{2} / \mathrm{g}\right)\end{array}$ \\
\hline SBA-15 & 0 & 70.2 & 0 & 0 & 0 & 0 & 29.8 & 826 \\
\hline $\begin{array}{l}\text { APTMS- } \\
\text { SBA-15 }\end{array}$ & 3.9 & 39.0 & 0 & 5.8 & 25.7 & 5.1 & 20.5 & 70 \\
\hline Deca & 0 & 36.7 & 15.2 & 8.3 & 39.8 & 0 & 0 & 1.5 \\
\hline $\begin{array}{l}\text { Deca- } \\
\text { SBA-15 }\end{array}$ & 1.2 & 50.6 & 0.9 & 4.0 & 17.1 & 2.2 & 24,0 & 48 \\
\hline $\begin{array}{l}\text { VOJ } \\
\text { SBA-15 }\end{array}$ & 0 & 68.3 & 0.7 & 0 & 0 & 0 & 31.0 & 445 \\
\hline
\end{tabular}

Moreover, the decrease in the $\mathrm{Cl} / \mathrm{N}$ ratio when going from APTMS-SBA-15 to deca-SBA-15 clearly demonstrates that 
anion exchange has taken place. On the basis of the resulting $\mathrm{V} / \mathrm{N}$ ratio of 0.22 , which results in the formation of 2.7 wt $\%$ V/SBA-15, the upper limit for loading SBA-15 with vanadia using the above procedure can be determined as $20.5 \mathrm{wt} \% \mathrm{~V} / \mathrm{SBA}-15$. This result is in excellent agreement with the experimentally determined value $(22 \mathrm{wt} \% \mathrm{~V})$ for the saturation loading [33]. Furthermore, it demonstrates the potential of this approach to precisely control the amount of vanadium introduced into SBA-15 over a broad range of vanadia loadings. The survey spectrum of decaSBA-15 resembles that of APTMS-SBA-15, which suggests that the organic matrix has not been modified during the incorporation of decavanadate as discussed in more detail below. This is illustrated by the $\mathrm{N} / \mathrm{C}$ ratio, which was observed to be comparable before and after the anion exchange reaction (see Table 1). In part (e), the spectrum of the final catalyst, $2.7 \mathrm{wt} \% \mathrm{~V} / \mathrm{SBA}-15$, is shown. Besides the presence of the V2p peaks (see Fig. 6 for detailed $\mathrm{V} 2 \mathrm{p}_{3 / 2}$ XPS spectra), the spectrum resembles that of part (a) as far as position and intensity of the observed peaks are concerned. Note that no carbon peak was observed for $\mathrm{VO}_{\mathrm{x}} / \mathrm{SBA}-15$, which indicates that during the calcination step essentially all organic residues were removed. Besides this, neither chlorine nor sodium was detected in the final material by XPS. The nitrogen isotherms of SBA-15, decaSBA-15 and $\mathrm{VO}_{\mathrm{x}} / \mathrm{SBA}-15$ are shown in Fig. 2. All isotherms are of type IV exhibiting a H1-type hysteresis loop, which is typical of mesoporous materials. The results of the physisorption characterization reveal pore diameters of 7.16 and $6.52 \mathrm{~nm}$ for SBA-15 and the $\mathrm{VO}_{\mathrm{x}} / \mathrm{SBA}-15$ (see Table 2), respectively, as well as a value of $4.75 \mathrm{~nm}$ for the modified surface (deca-SBA-15). With vanadia loading, the surface area, pore radius and pore volume shift to lower values. However, BET reveals that in the presence of vanadium oxide the mesoporous channels remain accessible. Previously we have shown that the pore radius and pore volume decrease significantly with vanadium loading which suggests that the vanadia species are located inside the pores of SBA-15, coating the inner walls of the mesoporous matrix [33]. As indicated by X-ray diffraction and TEM (not shown) of the final $\mathrm{VO}_{\mathrm{x}} / \mathrm{SBA}-15$ material, the pore structure of SBA-15 is conserved throughout the synthesis $[33,9]$.

Table 2: BET characteristics of the synthesized SBA-15 supported vanadium oxide compared to the blank SBA-15 support

\begin{tabular}{lllllll}
\hline & $\begin{array}{l}V \\
(\mathrm{wt} / \%)\end{array}$ & $\begin{array}{l}V \\
\left(\mathrm{~nm}^{2}\right)\end{array}$ & $\begin{array}{l}V \\
(\mathrm{mmol} / \mathrm{g})\end{array}$ & $\begin{array}{l}S_{\mathrm{BET}} \\
\left(\mathrm{m}^{2} / \mathrm{g}\right)\end{array}$ & $\begin{array}{l}r_{\mathrm{p}} \\
(\mathrm{mm})\end{array}$ & $V_{\mathrm{p}}(\mathrm{mL} / \mathrm{g})$ \\
\hline SBA-15 & 0.0 & 0.0 & 0.0 & 826 & 3.58 & 0.72 \\
VO_/SBA-15 & 2.7 & 0.7 & 0.53 & 445 & 3.26 & 0.43 \\
\hline
\end{tabular}

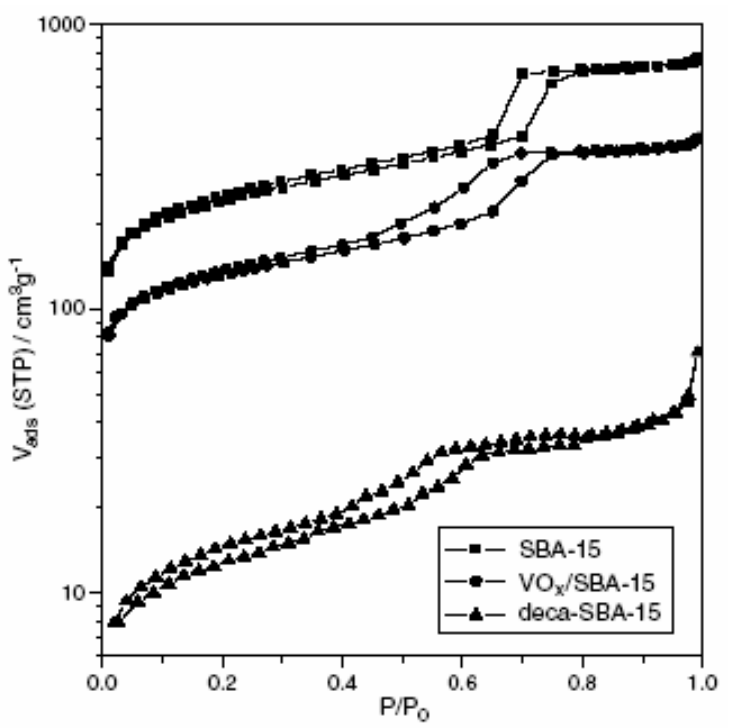

Figure 2: $\mathrm{N}_{2}$ isotherms of SBA-15, deca-SBA-15 and 2.7 wt $\%$ V/SBA- 15 .

\section{3. $X P S$}

\subsubsection{APTMS-SBA-15}

Fig. 3 shows the high-resolution C1s (left panel) and N1s (right panel) spectra of APTMS-SBA-15 together with the results from the peak-fitting procedure. Table 3 summarizes the binding energies, FWHM, and fractions of the corresponding peaks. The $\mathrm{C} 1 \mathrm{~s}$ peaks at $286.8 \mathrm{eV}$ (26.4\%) and $288.7 \mathrm{eV}(4.3 \%)$ are assigned to carbon bound to a single oxygen and bicarbonate-type carbon, respectively. The other forms of carbon are represented by a peak at $285.4 \mathrm{eV}(69.3 \%)$. The fact that some bicarbonate-type carbon is observed although none was expected is indicative of the interaction of APTMS grafted onto the silica surface with $\mathrm{CO}_{2}$ and $\mathrm{H}_{2} \mathrm{O}$ which leads to the formation of a bicarbonate salt ( $\left.\mathrm{R}-\mathrm{NH}_{3}{ }^{+} \mathrm{HCO}_{3}{ }^{-}\right)$according to Eq.(1) [41]:

$\mathrm{R}-\mathrm{NH}_{2}+\mathrm{CO}_{2}+\mathrm{H}_{2} \mathrm{O} \rightarrow \mathrm{R}-\mathrm{NH}_{3}^{+} \mathrm{HCO}_{3}^{-}$

Therefore, the peak at $288.7 \mathrm{eV}$ is assigned to bicarbonate. The contribution of carbonyl-type carbon in APTMSSBA15 amounts to $1.1 \%$ (see Tables 1 and 3). Therefore, based on the $\mathrm{C} / \mathrm{N}$ ratio for bicarbonate of $1,22 \%$ of the total amount of nitrogen present as $\mathrm{NH}_{3}{ }^{+}$is formed according to Eq. (1). The $\mathrm{C}-\mathrm{O}$ peak at $286.8 \mathrm{eV}$ is assigned to methoxy, in agreement with reported $\mathrm{C} 1 \mathrm{~s}$ binding energies for alkoxy groups bound to $\mathrm{Si}$ [42]. Based on the fit results, the ratio of propyl carbon $(\mathrm{C}-\mathrm{C})$ to nitrogen was determined as 3.07. This result nicely demonstrates that the sample was essentially free from carbon impurities. 



Figure 3: XP C1s (left panel) and XP N1s (right panel) spectra of APTMS-SBA-15 together with the results from the peakfitting procedure.

Table 3: Results from the analysis of the high-resolution XPS spectra

\begin{tabular}{|c|c|c|c|c|c|c|c|c|}
\hline & & \multicolumn{3}{|l|}{$\mathrm{Cls}$} & \multicolumn{2}{|l|}{ N1s } & \multicolumn{2}{|c|}{$\mathrm{V} 2 \mathrm{p}_{3 / 2}$} \\
\hline & & $\mathrm{C}-\mathrm{C}$ & $\mathrm{C}-\mathrm{O}$ & $\mathrm{HCO}_{3}^{-}$ & $\mathrm{NH}_{2}$ & $\mathrm{NH}_{3}^{+}$ & $\mathrm{v}^{3+}$ & $v^{5+}$ \\
\hline \multirow[t]{3}{*}{ APTMS-SBA-15 } & BE & 285.4 & 286.8 & 288.7 & 399.5 & 402 & & \\
\hline & FWHM & 2.2 & 1.9 & 2.1 & 2.1 & 2.2 & & \\
\hline & $\%$ & 69.3 & 26.4 & 4.3 & 14.3 & 85.7 & & \\
\hline \multirow[t]{2}{*}{ Deca-SBA-15 } & BE & 285.3 & 286.6 & 288.0 & 400.2 & 402.2 & 515.9 & 517.2 \\
\hline & FWHM & 2.3 & 1.9 & 2.2 & 2.7 & 2.2 & 2.3 & 2.3 \\
\hline \multirow[t]{3}{*}{$260 \mathrm{~min}$} & $\%$ & 71.6 & 21.4 & 7 & 72.2 & 27.8 & 46.8 & 53.2 \\
\hline & $\mathrm{BE}$ & 285.3 & 286.6 & 288.0 & 400.2 & 402.2 & 515.9 & 517.2 \\
\hline & FWHM & 2.3 & 1.9 & 2.4 & 2.5 & 2.4 & 2.3 & 2.3 \\
\hline $30 \mathrm{~min}$ & $\%$ & 70.8 & 19.5 & 9.7 & 39.9 & 60,1 & 20.6 & 79.4 \\
\hline \multirow[t]{3}{*}{$\mathrm{VO}_{x} / \mathrm{SBA}-15$} & BE & & & & & & 515.9 & 517.3 \\
\hline & FWHM & & & & & & 2.2 & 2.0 \\
\hline & $\%$ & & & & & & 24.1 & 75.9 \\
\hline
\end{tabular}

The binding energy (BE/eV), FWHM (eV), and fraction (\%) given were determined from the integrals of the Gauss-Lorentz fit functions shown in Figs. 3-6.

Previous studies on 3-aminopropyltriethoxysilane (APTS) adsorption on hydrated amorphous silica have shown that the APTS molecules are predominantly in their bidentate and tridentate form (with two and three $\mathrm{Si}-\mathrm{O}-\mathrm{Si}$ bonds, respectively) [34]. Also the contribution from nonhydrolyzed monodentate was found to be small, while the hydrolyzed monodentate form was absent. Based on steric reasons it was concluded that three covalent bonds with the surface can be excluded implying polymerization of tridentate APTS. From the results of the area fits, the ratio of carbon bound to oxygen $(\mathrm{C}-\mathrm{O})$ to nitrogen was determined as 1.17. These XPS results show that the majority of APTMS molecules were in their bidentate form with a contribution from monodentate APTMS. Previously, the influence of surface water in the reaction of APTS with silica gel was studied extensively using ${ }^{29} \mathrm{Si}$ NMR and DRIFTS [36]. It was shown that hydrolysis of the alkoxy groups was prevented and mainly bidentate but no polymerized (tridentate) APTS was formed, when all modification stages, the silica pretreatment, the reaction of silica with APTS, as well as the curing stage were performed under dry/vacuum conditions. Although the present experiments were conducted under comparable conditions as above, an additional reaction step, the formation of the ammonium salt of APTMS, was performed before the sample was dried and examined with XPS. As this reaction was conducted in (aqueous) $\mathrm{HCl}$ solution, the presence of a small amount of tridentate APTMS cannot be excluded.

The right panel of Fig. 3 displays the N1s spectrum of APTMS-SBA-15. The peak consists of two components centered at $399.5 \mathrm{eV}$ and $402.0 \mathrm{eV}$. In agreement with the literature, the former is attributed to the free amine group $\left(\mathrm{R}-\mathrm{NH}_{2}\right)$ and the latter is attributed to a protonated amino group $\left(\mathrm{R}-\mathrm{NH}_{3}{ }^{+}\right)[41,43]$. Quantitative analysis of the N1s peak yields that $85.7 \%$ of the amine is present in its protonated form and $14.3 \%$ as free amine (see Table 3). As can be seen from Table 1 , the amount of $\mathrm{NH}_{3}{ }^{+}$closely matches the amount of chlorine as would be expected from the formation of the ammonium chloride. Previous work on alkylamine-silanized metal oxides has shown that some nitrogen, which is present in form of amine $\left(\mathrm{NH}_{2}\right)$, resists protonation in acid solution [44]. It has been suggested that these amino groups are associated with hydrogen bonding between amino groups and surface hydroxyl. On the other hand, amine protonated while in contact with the acid solution is possibly deprotonated when dried or placed in vac- 
uum, which results in a decreased ratio $\mathrm{NH}_{3}{ }^{+} / \mathrm{NH}_{2}$. In experiments in which the exposure time was reduced to 30 min (compared to $260 \mathrm{~min}$ ), a slightly higher fraction of $\mathrm{NH}_{3}{ }^{+}$of $89.3 \%$ (compared to $85.7 \%$ ) was obtained, ind cating that the influence of the analysis conditions on the ratio $\mathrm{NH}_{3}{ }^{+} / \mathrm{NH}_{2}$ was only minor for this sample.

\subsubsection{Deca-SBA-15}

The C1s XP spectrum (not shown) of deca-SBA-15 strongly resembles that of APTMS-SBA-15. The C1s peak consists of three components which are centered at 285.3 eV (71.6\%), $286.6 \mathrm{eV}$ (21.4\%), and $288.0 \mathrm{eV}$ (7\%) (see Table 3). As discussed above, they can be assigned to carbon, which is part of the propyl chain $(\mathrm{C}-\mathrm{C})$, carbon bound to a single oxygen atom $(\mathrm{C}-\mathrm{O})$, and bicarbonatetype carbon, respectively. Based on the ratio of propyl carbon $(\mathrm{C}-$ C) to nitrogen of 3.05 , there is no indication for the presence of carbon impurities. However, a slightly different intensity distribution is observed indicating chemical transformations within the organic framework during the anion exchange reaction. For deca-SBA-15, the ratio of methoxy carbon $(\mathrm{C}-\mathrm{O})$ to nitrogen was determined as 0.91 , which suggests that the majority of APTMS was present in its bidentate form. By comparison with the higher $\mathrm{C} / \mathrm{N}$ ratio of 1.17 obtained for APTMS-SBA-15, this result implies the hydrolysis of part of the methoxy groups. However, based on the XPS results, a contribution from polymerized APTMS cannot be ruled out, as previous experiments have shown an increase in the amount of polymerized silane molecules with increasing exposure to water during the modification of silica with APTS [34].

Fig. 4 depicts N1s XP spectra of deca-SBA-15. They were obtained after exposure of the sample to the X-ray beam for $30 \mathrm{~min}$ and $260 \mathrm{~min}$, respectively. Both spectra can be described by a sum of two components centered at 400.2 and $402.2 \mathrm{eV}$. As discussed above, they are attributed to the free amine group $\left(\mathrm{NH}_{2}\right)$ and to a protonated amino group $\left(\mathrm{NH}_{3}{ }^{+}\right)$, respectively. After $30 \mathrm{~min}$ of exposure, significantly more $\mathrm{NH}_{3}{ }^{+}(60.1 \%)$ than $\mathrm{NH}_{2}(39.9 \%)$ was observed. Clearly, longer exposure times lead to a strong decrease of the ratio $\mathrm{NH}_{3}{ }^{+} / \mathrm{NH}_{2}$ from 1.51 to 0.39 . This is indicative of a conversion of $\mathrm{NH}_{3}{ }^{+}$into $\mathrm{NH}_{2}$ as result of the measurement process, i.e. the X-ray beam and/or vacuum. Such a pronounced alteration of the protonated amino group was only observed in case of the deca-SBA-15 sample, whereas APTMS-SBA-15 was much more stable.

Detailed XPS spectra of the V2p region of decaSBA-15 are shown in Fig. 5. Fig. 5 depicts spectra of decaSBA-15 after exposure to the X-ray beam for 30 min (bottom) and $260 \mathrm{~min}$ (top) together with the spectrum of blank SBA-15. As the spectrum of SBA-15 shows structure in the $V 2 p$ region, it was used for background subtraction. The resulting spectra of the $\mathrm{V} 2 \mathrm{p}_{3 / 2}$ region are shown as inset of Fig. 5. Both spectra can be described as the sum of two components centered at $517.2 \mathrm{eV}$ (A) and $515.9 \mathrm{eV}$ (B).

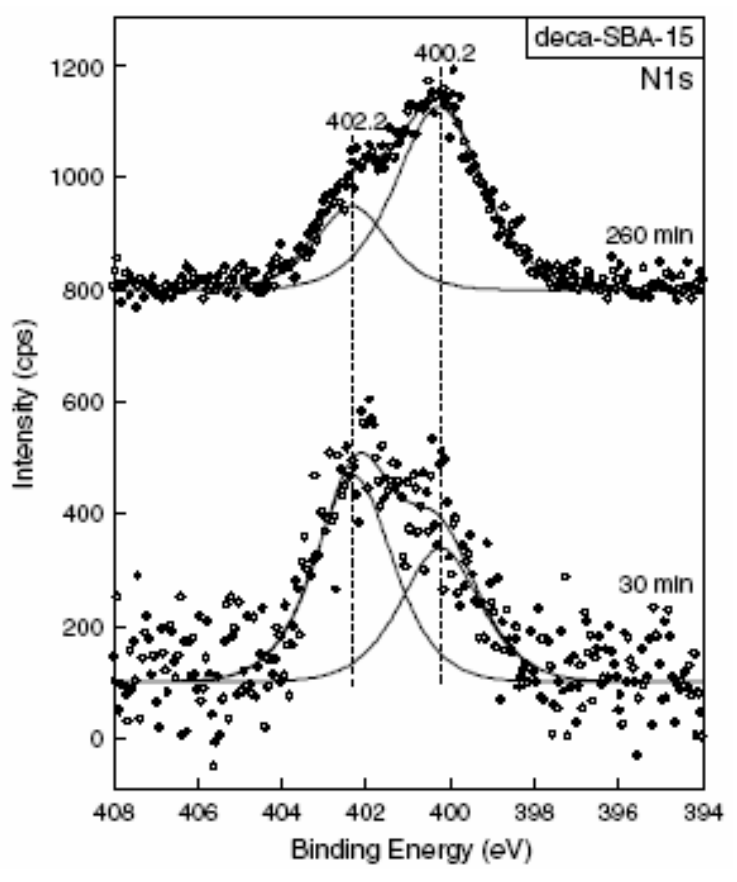

Figure 4: XP N1s spectra of deca-SBA-15 after $30 \mathrm{~min}$ and $260 \mathrm{~min}$ together with the results from the peak-fitting procedure. The spectra are offset for clarity.

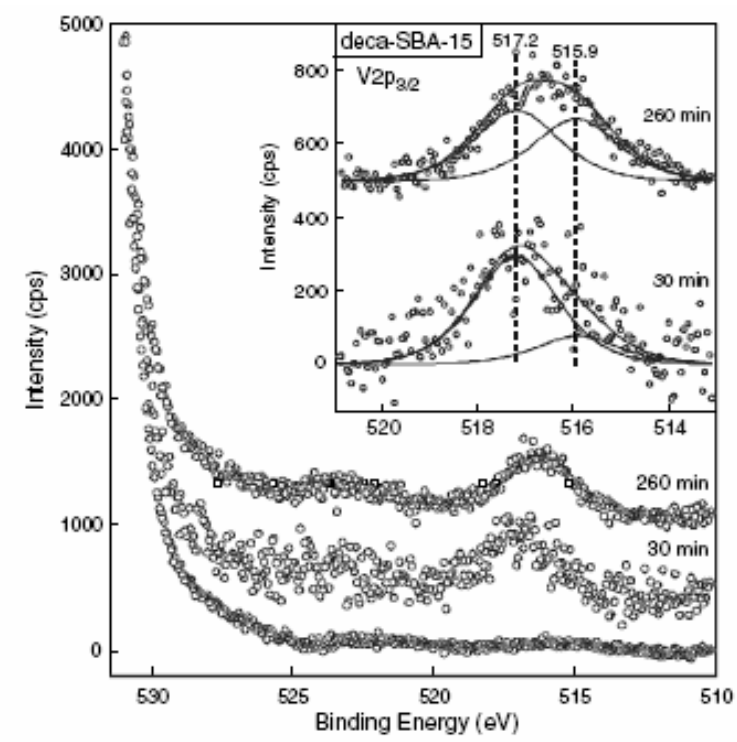

Figure 5: XP spectra of deca-SBA-15 after $30 \mathrm{~min}$ and 260 min (upper curves) and blank SBA-15 (lower curve). The $\mathrm{V} 2 \mathrm{p}_{3 / 2}$ region of the resulting difference spectra is shown as inset together with the results from the peak-fitting procedure. For details see text.

The position of component $A$ agrees well with the $V 2 p_{3 / 2}$ binding energy we have observed for $\mathrm{V}_{2} \mathrm{O}_{5}$, in which vanadium is expected to be in its highest oxidation state $(+5)$. Therefore, we attribute component $\mathrm{A}$ to the $\mathrm{V}^{5+}$ oxidation state. As the absolute values of the binding energies of vanadium in all oxidation states vary significantly in the 
literature, the assignment of component $\mathrm{B}$ was based on the reported differences in the binding energies, DBE, of $\mathrm{V}^{5+}$ and lower oxidation states. Generally, the reported DBE between $\mathrm{V}^{5+}$ and $\mathrm{V}^{4+}$ is $0.7-1.0 \mathrm{eV}$, and the reported DBE between $\mathrm{V}^{5+}$ and $\mathrm{V}^{3+}$ is $1.2-1.5 \mathrm{eV}[27,28,43,45,46]$. This suggests that component $\mathrm{B}$ corresponds to $\mathrm{V}^{3+}$. Quantitative analysis of the $\mathrm{V} 2 \mathrm{p}_{3 / 2}$ peak yields that $53.2 \%$ of the total $\mathrm{V}$ is present as $\mathrm{V} 5+$ and $46.8 \%$ is present as $\mathrm{V}^{3+}$. It is mentioned in the literature that prolonged exposure to X-rays can lead to a reduction of vanadium oxides [47]. Here, the reduction of decavanadate incorporated into SBA-15 (decaSBA-15) is directly observed while the organic framework stays intact (see Table 3). When exposing the sample to Xrays for $260 \mathrm{~min}$, the reduction of vanadium is accompanied by a color change from orange to green. The green color is characteristic for $\mathrm{V}^{3+}$ in aqueous solution and points to the presence of water on the surface of deca-SBA15. On the other hand, it is well known that vanadium retains its oxidation state $(5+)$ in air. The observed $\mathrm{V}^{3+}$ contribution to the $V 2 p_{3 / 2}$ peak can therefore be attributed to the reduction of $\mathrm{V}^{5+}$ during the XPS measurement. These experiments clearly demonstrate that extreme care has to be taken when XPS is used to determine oxidation states of vanadia catalysts.

\subsection{3. $V O_{x} / S B A-15$}

After calcination of the precursor material (decaSBA- 15), the oxidation state of $\mathrm{V}$ in the as-synthesized $\mathrm{VO}_{\mathrm{x}} /$ SBA-15 was investigated using XPS. Fig. 6 depicts detailed XP spectra of the V2p region of $2.7 \mathrm{wt} \% \mathrm{~V} / \mathrm{SBA}-$ 15 together with that of blank SBA-15. As explained above, the spectrum of SBA-15 shows was used for background subtraction. The resulting spectrum of the $V 2 p_{3 / 2}$ region is shown as inset of Fig. 6. Its peak can be described by two components centered at $517.3 \mathrm{eV}$ and $515.9 \mathrm{eV}$, which are assigned to $\mathrm{V}^{5+}$ and $\mathrm{V}^{3+}$, respectively. As discussed above, the observed $\mathrm{V}^{3+}$ contribution to the V2 $\mathrm{p}_{3 / 2}$ peak is attributed to the reduction of V5+ during the XPS measurement. Quantitative analysis yields that for $\mathrm{VO}_{\mathrm{x}} / \mathrm{SBA}-1575.9 \%$ of the total $\mathrm{V}$ is present as $\mathrm{V}^{5+}$ and $24.1 \%$ is present as $\mathrm{V}^{3+}$ (see Table 3 ). These results show that the $\mathrm{VO}_{\mathrm{x}} / \mathrm{SBA}-15$ sample is more stable regarding the reduction of $\mathrm{V}^{5+}$ as deca-SBA-15.

\subsection{Raman}

Fig. 7 shows a series of low-frequency Raman spectra obtained during the synthesis of $2.7 \mathrm{wt} \% \mathrm{~V} / \mathrm{SBA}-15$. As discussed previously [33], the spectrum of blank SBA-15 (spectrum (a)) shows Raman features around 485 and 977 $\mathrm{cm}^{-1}$, which are attributed to cyclic tetrasiloxane rings of the silica support (D1 defect mode) [48] and the $\mathrm{Si}-\mathrm{OH}$ stretching vibration of surface hydroxyl groups [49], respectively. In addition, weaker Raman bands appeared around $600 \mathrm{~cm}^{-1}$ and $810 \mathrm{~cm}^{-1}$, which are assigned to cyclic trisiloxane rings (D2 defect mode) and the symmetrical

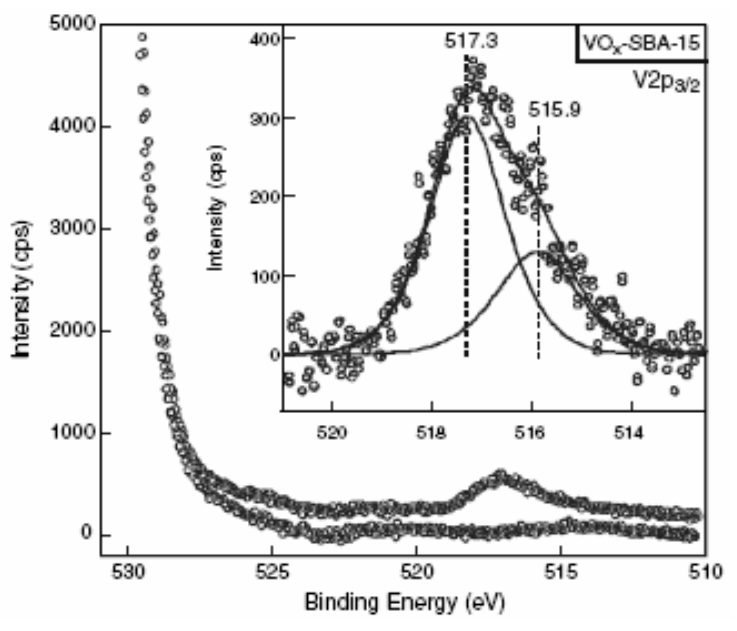

Figure 6: XP spectra of $2.7 \mathrm{wt} \% \mathrm{~V} / \mathrm{SBA}-15$ (upper curve) and blank SBA-15 (lower curve). The $\mathrm{V} 2 \mathrm{p}_{3 / 2}$ region of the resulting difference spectrum is shown as inset together with the results from the peak-fitting procedure. For details see text.

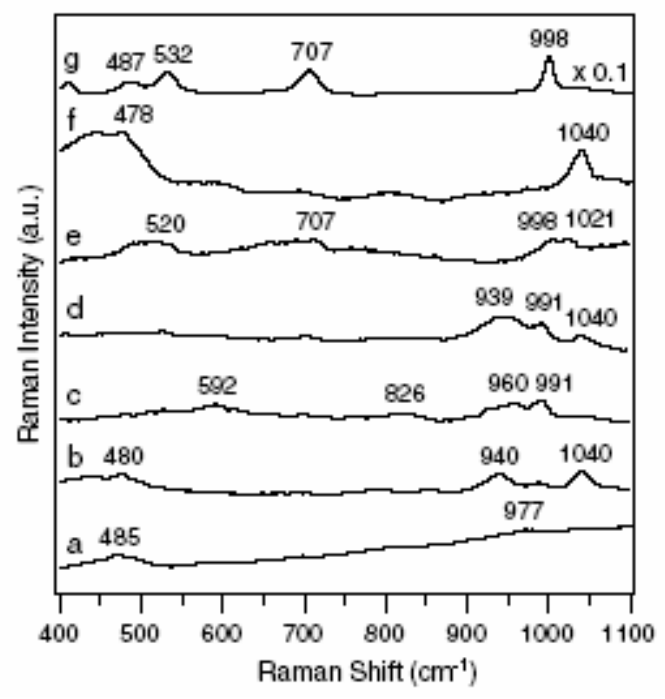

Figure 7: 7. Raman spectra showing the low-frequency region of (a) SBA-15, (b) APTMS-SBA-15, (c) deca, (d) deca-SBA-15, (e) $2.7 \mathrm{wt} \% \mathrm{~V} / \mathrm{SBA}-15$ under ambient conditions, (f) dehydrated $2.7 \mathrm{wt} \% \mathrm{~V} / \mathrm{SBA}-15$, and (g) crystalline V2O5. The spectra are offset for clarity.

Si-O-Si stretching mode, respectively [49]. Functionalization of SBA-15 with APTMS and subsequent transformation into the ammonium salt leads to the appearance of new major bands at 940 and $1040 \mathrm{~cm}^{-1}$, respectively (spectrum (b)). They are assigned to $\mathrm{CH}_{2}$ rocking and $\mathrm{C}-\mathrm{C}$ stretch vibrations of the propylammonium group, respectively [50,51]. Spectrum (c) corresponds to deca, which shows Raman bands at 592, 826, 960 and $991 \mathrm{~cm}^{-1}$, respectively, in good agreement with those reported for sodium decavanadate $\left(\mathrm{Na}_{6} \mathrm{~V}_{10} \mathrm{O}_{28} \times 18 \mathrm{H}_{2} \mathrm{O}\right)$ [52]. The spectrum of decaSBA-15, spectrum (d), is characterized by Raman bands at 596, 939, 991 and $1040 \mathrm{~cm}^{-1}$, respectively. Qualitatively, 
spectrum (d) can be considered as a superposition of spectra (b) and (c). As discussed above and also confirmed by Raman spectra of the high-frequency region of deca (see Fig. 8), the functionalized SBA-15 is unaffected by the anion exchange. These results demonstrate that Raman spectroscopy allows for the unambiguous identification of decavanadate in the pores of the silica matrix, as its vibrational signature is distinctly different from that of other vanadia compounds, e.g. $\mathrm{V}_{2} \mathrm{O}_{5}$ (see spectrum $(\mathrm{g})$ ). Thermal decomposition of deca-SBA-15 yields the product of the synthesis, $2.7 \mathrm{wt} \% \mathrm{~V} / \mathrm{SBA}-15$. Its Raman spectrum (see spectrum (e)) clearly differs from that of deca-SBA-15 and shows bands at 520,656, 707, 998 and $1021 \mathrm{~cm}^{-1}$, respectively. Previously, similar bands were assigned to hydrated surface vanadium oxide species forming a $\mathrm{V}_{2} \mathrm{O}_{5} \times \mathrm{nH}_{2} \mathrm{O}$ gel due to the close resemblance with the Raman bands observed for $\mathrm{V}_{2} \mathrm{O}_{5} \times \mathrm{nH}_{2} \mathrm{O}$ xerogel [53]. Raman spectrum (f) corresponds to $2.7 \mathrm{wt} \% \mathrm{VO}_{\mathrm{x}} / \mathrm{SBA}-15$ after dehydration. It is dominated by a $\mathrm{V}=\mathrm{O}$ stretchingband at $1040 \mathrm{~cm}^{-1}$, which has been assigned to vanadium in a tetrahedral coordination [15,17-20]. No $\mathrm{V}_{2} \mathrm{O}_{5}$-related bands (see spectrum $(\mathrm{g}$ ) for comparison) were observed demonstrating the highly dispersed state of the anchored vanadium oxide species.

Fig. 8 depicts the high-frequency region of the Raman spectra obtained during the synthesis of $2.7 \mathrm{wt} \%$ V/SBA- 15. As reference, the spectrum of blank SBA-15 (spectrum (a)) and methoxy adsorbed on SBA-15 (spectrum (c)) are shown. Methoxy adsorbed on SBA-15 gives rise to two Raman bands at $2862 \mathrm{~cm}^{-1}$ and $2963 \mathrm{~cm}^{-1}$, which are characteristic of $\mathrm{C}-\mathrm{H}$ stretching vibrations of a methoxy group. After grafting of APTMS onto SBA-15 and subs quent formation of the ammonium salt (APTMSSBA- 15) spectrum (b) was obtained. As can be seen from spectrum (b), no major Raman intensity is observed in the region around $2860 \mathrm{~cm} \_1$, which suggests that a large fraction of the methoxy groups of APTMS has reacted. Spectrum (b) shows broad bands at $\sim 2900,2926$ and $2973 \mathrm{~cm}^{-1}$, respectively, which are attributed to $\mathrm{C}-\mathrm{H}$ stretch vibrations of the three $\mathrm{CH}_{2}$ groups [54]. As each of the methylene groups is in a different chemical environment, we expect the $\mathrm{C}-\mathrm{H}$ stretch bands to appear at different frequencies. The ion exchange of decavanadate for chloride does not affect the high-frequency region of the spectrum (see spectrum (d)). After the final steps of the synthesis, the thermal decomposition of decavanadate and formation of $\mathrm{VO}_{\mathrm{x}} / \mathrm{SBA}-15$, no high-frequency Raman bands were observed (see spectrum (e)). The absence of $\mathrm{C}-\mathrm{H}$-related stretching bands suggests that the grafted ammoniumpropyl is removed during the thermal treatment as confirmed by XPS and DRIFTS (see below).

The last step of the synthesis, i.e. the anchoring of the vanadia precursor to the silica surface during calcination, was also studied using vibrational spectroscopy. Fig. 9 shows visible Raman spectra of the final catalytic material, $2.7 \mathrm{wt} \% \mathrm{~V} / \mathrm{SBA}-15$, and blank SBA-15. They were recorded at room temperature after dehydration in flowing air at $400{ }^{\circ} \mathrm{C}$ for $1 \mathrm{~h}$. The spectrum of blank SBA-15 is charac- terized by a Raman feature at $980 \mathrm{~cm}^{-1}$, which is attributed to the $\mathrm{Si}-\mathrm{OH}$ stretch of surface hydroxyl groups, as discussed above. In contrast, the spectrum of $2.7 \mathrm{wt} \% \mathrm{~V} /$ SBA-15 is dominated by the $\mathrm{V}=\mathrm{O}$ stretching band at 1040 $\mathrm{cm}^{-1}$ (see above). After loading of vanadia, the hydroxyl band at $980 \mathrm{~cm}^{-1}$ is not observed anymore. This demonstrates that the vanadia precursor is anchored to the silica support via surface hydroxyl groups. It should be noted that a quantitative analysis is difficult due to the fact that the surface area is significantly reduced in the course of the synthesis of $\mathrm{VO}_{\mathrm{x}} / \mathrm{SBA}-15$ (see Table 2).

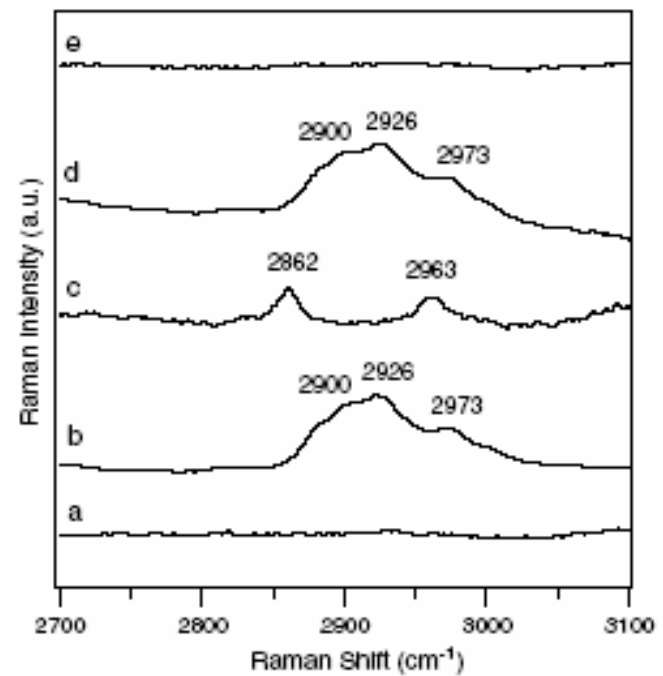

Figure 8: Raman spectra showing the high-frequency region of (a) SBA-15, (b) APTMS-SBA-15, (c) methoxy adsorbed on SBA-15, (d) deca-SBA-15, and (e) $2.7 \mathrm{wt} \%$ V/SBA-15 under ambient conditions. The spectra are offset for clarity.

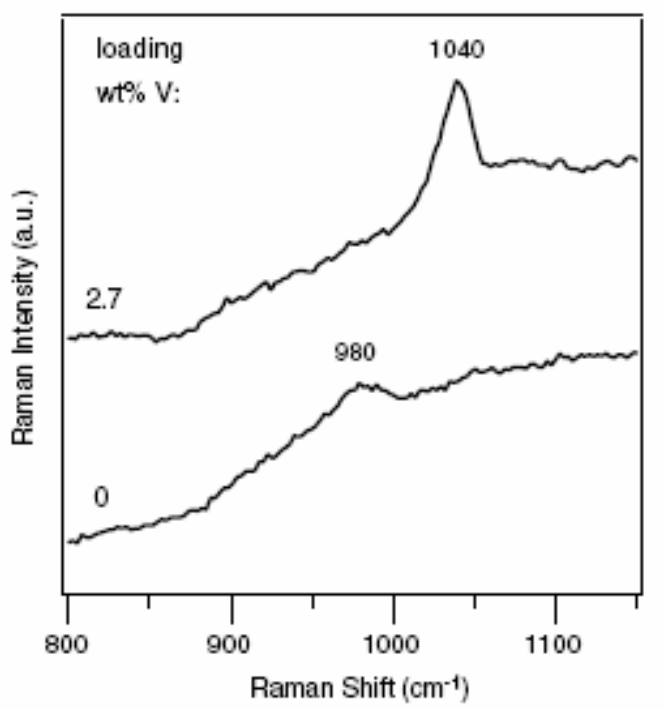

Figure 9: Raman spectra of dehydrated $2.7 \mathrm{wt} \% \mathrm{~V} / \mathrm{SBA}-15$ and SBA-15. The spectra are offset for clarity. 


\subsection{DRIFTS}

Fig. 10 shows DRIFT spectra of (a) SBA-15, (b) APTMSSBA-15, (c) deca-SBA-15, and (d) $2.7 \mathrm{wt} \% \mathrm{~V} / \mathrm{SBA}-15$ under ambient conditions. The high-frequency region shows a narrow band at $3746 \mathrm{~cm}^{-1}$, which is assigned to free silanols. The broad band at $3200-3600 \mathrm{~cm}^{-1}$ is attributed to the presence of bridged silanols or physisorbed water trapped in the pores of the silica matrix [34]. The functionalization of SBA-15 with APTMS, i.e. the formation of APTMS-SBA-15, results in dramatic changes of the DRIFT spectrum. The low-frequency region shows a pattern of infrared bands between 1300 and $1500 \mathrm{~cm}^{-1}$, which are characteristic for APTMS modified silica [34]. The bands at 1392, 1413, 1447 and $1472 \mathrm{~cm}^{-1}$ are attributed to bending vibrations of $\mathrm{CH}_{3}, \mathrm{Si}-\mathrm{CH}_{2}, \mathrm{CH}_{3}$ and $\mathrm{CH}_{2}$, respectively, while the bands at 2881 and $2938 \mathrm{~cm}^{-1}$ are assigned to $\mathrm{CH}_{2}$ stretching vibrations. All the above band positions are in excellent agreement with those reported previously [34]. The band at $3046 \mathrm{~cm}^{-1}$ is characteristic of $\mathrm{N}-\mathrm{H}$ stretching vibrations in $\mathrm{NH}_{3}{ }^{+}$, and the pair of broad bands at $3240 \mathrm{~cm}^{-1}$ and $3410 \mathrm{~cm}^{-1}$ is attributed to $\mathrm{N}-\mathrm{H}$ stretching vibrations in $\mathrm{NH}_{2}$ [55]. Spectrum (c) corresponds to decaSBA-15. It largely resembles spectrum (b) in both parts of the spectrum shown in Fig. 10. This demonstrates that during the anion exchange reaction no changes in the structure of the organic framework occur, thereby nicely confirming the results from the above XPS and Raman measurements. Spectrum (d) corresponds to the product of the synthesis, $\mathrm{VO}_{\mathrm{x}} / \mathrm{SBA}-15$. All vibrations related to the organic framework have disappeared because of thermolysis or oxidation during the calcination step, in excellent agreement with the results from XPS and Raman spectroscopy.
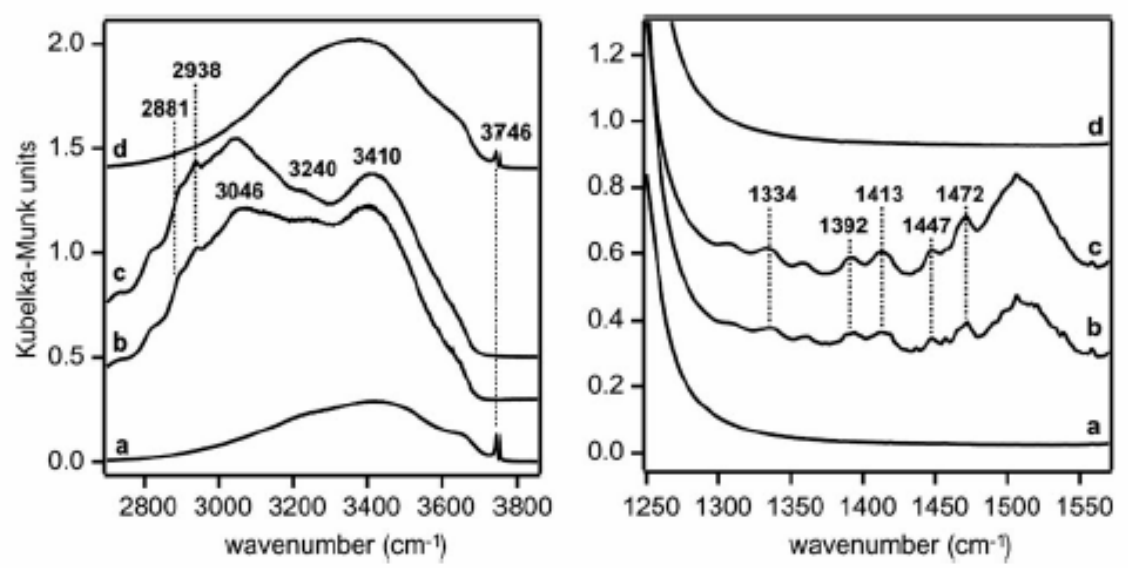

Figure 10: DRIFT spectra of (a) SBA-15, (b) APTMS-SBA-15, (c) deca-SBA-15, and (d) $2.7 \mathrm{wt} \%$ V/SBA-15 under ambient conditions. The spectra are offset for clarity.

a) ambient

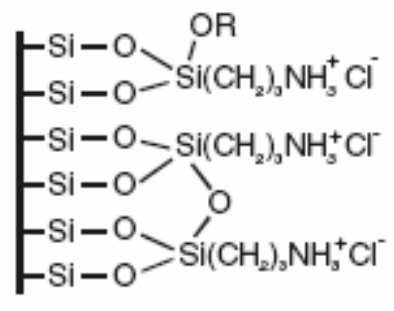

b) vacuum

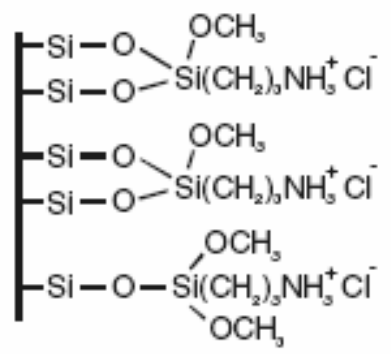

$\mathrm{R}=\mathrm{H}, \mathrm{CH}_{3}$

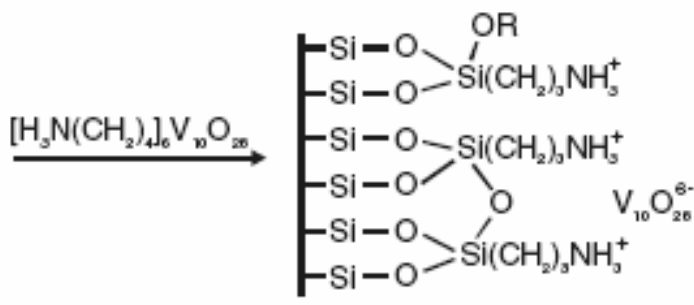

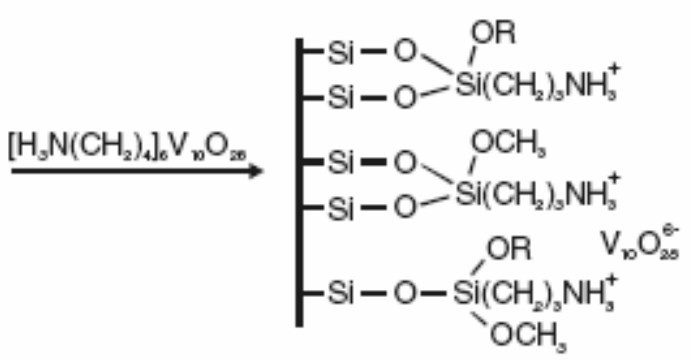

Scheme 1: Bonding models of APTMS-SBA-15 and deca-SBA-15 as observed under (a) ambient conditions and (b) vacuum. 


\section{Synthesis mechanism}

On the basis of the above-mentioned results, the following reaction mechanism is proposed: (1) The surface of SBA-15 is modified via its hydroxyl groups by grafting of 3-aminopropyltrimethoxy-silane (APTMS). Subsequent treatment with $\mathrm{HCl}$ results in the formation of the corresponding ammonium salt (APTMS-SBA-15). Under ambient conditions, the protonated APTMS is present in its bidentate and tridentate forms as shown in Scheme 1(a) [56]. In UHV, however, the majority of protonated APTMS molecules adopt the monodentate and bidentate forms (see Scheme 1(b)). (2) During the anion exchange reaction, decavanadate $\left(\mathrm{V}_{10} \mathrm{O}_{28}{ }^{26-}\right)$ is incorporated intactly into the pores of the silica matrix without structural changes of the organic framework. In vacuum, however, a smaller fraction of methoxy is present in the case of deca indicating partial hydrolysis during the anion exchange reaction (see Scheme 1(b)). (3) Thermal decomposition of the decavanadate precursor material yields the final supported vanadia catalyst ( $\left.\mathrm{VO}_{\mathrm{x}} / \mathrm{SBA}-15\right)$. During this process, all organic residues as well as chlorine and sodium are completely removed from the pores. Vanadia is anchored onto the surface of SBA-15 via reaction with silanol groups.

\section{Conclusion}

The synthesis of highly dispersed vanadia supported on mesoporous silica SBA-15 has been studied in detail by using a combination of X-ray photoelectron spectroscopy (XPS) and vibrational spectroscopy. In the first step of the synthesis, APTMS is grafted onto the surface via hydroxyl groups as shown by XPS. Subsequent treatment with $\mathrm{HCl}$ solution results in the formation of the corresponding ammonium salt (APTMS-SBA-15) as proven by the C1s and N1s XPS spectra. The $\mathrm{C}-\mathrm{C}$ stretch and $\mathrm{C}-\mathrm{H}$ stretch bands in the Raman spectrum confirm the presence of the propyl chain. Also, DRIFTS shows a vibrational signature charac-

\section{References}

[1] D.Y. Zhao, J.L. Feng, Q.S. Huo, N. Melosh, G.H. Fredrickson, B.F. Chmelka, G.D. Stucky, Science 279 (1998) 548.

[2] K. Cassiers, T. Linssen, M. Mathieu, M. Benjelloun, K. Schrijnemakers, P. Van der Poort, P. Cool, E.F. Vansant, Chem. Mater. 14 (2002) 2317.

[3] J. Jarupatrakorn, T.D. Tilley, J. Am. Chem. Soc. 124 (2002) 8380.

[4] Y.-M. Liu, Y. Cao, K.-K. Zhu, S.-R. Yan, W.-L. Dai, H.-Y. He, K.-N. Fan, Chem. Commun. (2002) 2832.

[5] H.H. Lopez, A. Martinez, Catal. Lett. 83 (2002) 37.

[6] Y. Segura, P. Cool, P. Kustrowski, L. Chmielarz, R. Dziembaj, E.F. Vansant, J. Phys. Chem. B 109 (2005) 12071.

[7] D.A. Ruddy, N.L. Ohler, A.T. Bell, T.D. Tilley, J. Catal. 238 (2006) 277.

[8] C. Hess, I.J. Drake, J.D. Hoefelmeyer, T.D. Tilley, A.T. Bell, teristic for APTMS modified silica. The fact that the highfrequency region of the Raman spectrum of APTMS-SBA15 does not show a major methoxy-related band suggests that under ambient conditions protonated APTMS is present in its bidentate and tridentate (polymerized) forms. XPS analysis revealed a strong influence of surface water on the resulting structure of APTMS. In UHV, i.e. under dry conditions, the protonated APTMS molecules adopt the monodentate and bidentate form. During the anion exchange reaction, decavanadate is incorporated intactly into the pores as evidenced by the presence of the characteristic $\mathrm{V}=\mathrm{O}$ stretch Raman band of decavanadate at $991 \mathrm{~cm}^{-1}$. No changes in the structure of the organic framework were observed. However, XPS analysis of deca-SBA-15 reveals a smaller fraction of methoxy compared to APTMS-SBA15 , which is indicative of partial hydrolysis of methoxy during anion exchange. It is shown that calcination yields the final supported vanadia catalyst, while the organic residues as well as chlorine and sodium are fully removed from the pores. The vanadia precursor is grafted onto the surface of SBA-15 via hydroxyl groups as evidenced by the decrease in the Raman intensity of the silanol stretching band.

\section{Acknowledgement}

The authors wish to thank Mrs. Anja Hoffmann and Gisela Lorenz for kindly performing the BET measurements and Norbert Pfänder for performing the TEM measurements. C.H. thanks the Deutsche Forschungsgemeinschaft (DFG) for providing an Emmy Noether fellowship.
Catal. Lett. 105 (2005) 1.

[9] C. Hess, M.H. Looi, S.B. Abd Hamid, R. Schlo“ gl, Chem. Commun. (2006) 451.

[10] Q. Sun, J.M. Jehng, H.H. Hu, R.G. Herman, I.E. Wachs, K.J. Klier, J. Catal. 165 (1997) 91.

[11] S. Irusta, L.M. Cornaglia, E.E. Miro, E.A. Lombardo, J. Catal. 156 (1995) 167.

[12] D.S. Kim, J.A. Tatibouet, I.E. Wachs, J. Catal. 136 (1992) 209.

[13] G. Deo, I.E. Wachs, J. Haber, Crit. Rev. Surf. Chem. 40 (1994) 1.

[14] J.-M. Jeng, H. Hu, X. Gao, I.E. Wachs, Catal. Today 28 (1996) 335

[15] M. Banares, X. Gao, J.L.G. Fierro, I.E. Wachs, Stud. Surf. Sci. Catal. 110 (1997) 295.

[16] B. Jonson, B. Rebenstrof, R. Larsson, S.L. Andersson, J. 
Chem. Soc. Faraday Trans. 84 (1988) 1897.

[17] (a) M. Schraml-Marth, A. Wokaun, M. Pohl, H.L. Krauss, J. Chem. Soc. Faraday Trans. 87 (1991) 2635; (b) U. Scharf, M. Schraml-Marth, A. Wokaun, A. Baiker, J. Chem. Soc. Faraday Trans. 87 (1991) 3299.

[18] (a) K. Inumaru, T. Okuhara, M. Misono, N. Matsubayashi, H. Shimada, A. Nishijima, J. Chem. Soc. Faraday Trans. 88 (1992) 625; (b) K. Inumaru, T. Okuhara, M. Misono, J. Phys. Chem. 95 (1991) 4826; (c) K. Inumaru, T. Okuhara, M. Misono, N. Matsubayashi, H. Shimada, A. Nishijima, J. Chem. Soc. Faraday Trans. 87 (1991) 1807. 348 C. Hess et al. / Microporous and Mesoporous Materials 95 (2006) 339-349

[19] S. Xie, E. Iglesia, A.T. Bell, Langmuir 16 (2000) 7162.

[20] X. Gao, S.R. Bare, B. Weckhuysen, I.E. Wachs, J. Phys. Chem. B 102 (1998) 10842.

[21] N. Das, H. Eckert, H. Hu, I.E. Wachs, J.F. Walzer, F.J. Feher, J. Phys. Chem. 97 (1993) 8240.

[22] G.T. Went, S.T. Oyama, A.T. Bell, J. Phys. Chem. 94 (1990) 4240.

[23] F. Roozeboom, M.C. Mittelmeljer-Hazeleger, J.A. Mouljin, J. Medema, V.H.J. de Beer, P.J. Gellings, J. Phys. Chem. 84 (1980) 2783.

[24] G. Lische, W. Hanke, H.G. Jerschkewitz, J. Ohlmann, J. Catal. 91 (1985) 54.

[25] F. Arena, F. Frusteri, G. Martra, S. Coluccia, A. Parmaliana, J. Chem. Soc. Faraday Trans. 93 (1997) 3849.

[26] (a) S. Yoshida, T. Tanaka, Y. Nishimura, H. Mizutani, T. Funabiki, Proc. 9th Int. Congr. Catal., vol. 3, 1988, p. 1473; (b) S. Yoshida, T. Tanaka, T. Hanada, T. Hiraiwa, H. Kanai, T. Funabiki, Catal. Lett. 12 (1992) 277; (c) T. Tanaka, H. Yamashita, R. Tsuchitani, T. Funabiki, S. Yoshida, J. Chem. Soc. Faraday Trans. 84 (1988) 2987.

[27] N.K. Nag, F.E. Massoth, J. Catal. 124 (1990) 127.

[28] M.A. Eberhardt, A. Proctor, M. Houalla, D.M. Hercules, J. Catal. 160 (1996) 27, and references therein.

[29] K.L. Fudjala, T.D. Tilley, J. Catal. 216 (2003) 265.

[30] C. Coperet, M. Chabanas, R.P. Saint-Arroman, J.-M. Basset, Angew. Chem. 42 (2003) 15.

[31] K. Zhu, Z. Ma, Y. Zou, W. Zhou, T. Chen, H. He, Chem. Commun. (2001) 2552.

[32] R. Rulkens, J.L. Male, K.W. Terry, B. Olthof, A. Khadakov, A.T. Bell, E. Iglesia, T.D. Tilley, Chem. Mater. 11 (1999) 2966.

[33] C. Hess, J.D. Hoefelmeyer, T.D. Tilley, J. Phys. Chem. B 108 (2004) 9703.

[34] E.F. Vansant, P. Van der Voort, K.C. Vrancken, Characterization and Chemical Modification of the Silica Surface, Studies in Surface Science and Catalysis, vol. 93, Elsevier, Amsterdam, 1995, and references therein.

[35] Z. Luan, J.A. Fournier, J.B. Wooten, D.E. Miser, Micropor. Mesopor. Mater. 83 (2005) 150.

[36] K.C. Vrancken, P. Van der Voort, I. Gillis-D'Hamers, E.F. Vansant, P. Grobet, J. Chem. Soc. Faraday Trans. 88 (1992) 3197.
[37] W.A. Carvalho, M. Wallau, U. Schuchardt, J. Mol. Catal. A 144 (1999) 91.

[38] P. Roman, A. Aranzabe, A. Luque, J.M. Gutierrez-Zorilla, Mater. Res. Bull. 26 (1991) 731.

[39] (a) M. Klaasen, A. Berndtsson, J. Hedman, R. Nilsson, R. Nyholm, C. Nordling, J. Electron. Spectrosc. Relat. Phenom. 3 (1974) 427; (b) W.E. Morgan, J.R. Van Wazer, J. Phys. Chem. 77 (1973) 96; (c) T.L. Barr, Appl. Surf. Sci. 15 (1983) 1.

[40] D. Briggs, M.P. Seah, Practical Surface Analysis, Wiley, Chichester, 1990.

[41] K.M.R. Kallury, P.M. Macdonald, M. Thompson, Langmuir 10 (1994) 492.

[42] M.R. Horner, F.J. Boerio, H.M. Clearfield, J. Adhes. Sci. Technol. 6 (1992) 1.

[43] R.J. Colton, A.M. Guzman, J.W. Rabalais, Acc. Chem. Res. 11 (1978) 170.

[44] P.R. Moses, L.M. Wier, J.C. Lennox, H.O. Finklea, J.R. Lenhard, R.W. Murray, Anal. Chem. 50 (1978) 576.

[45] G.A. Sawatzky, D. Post, Phys. Rev. B 20 (1979) 1546.

[46] (a) S.L.T. Andersson, J. Chem. Soc. Faraday Trans. 75 (1979) 1356; (b) J.A. Odriozola, J. Soria, G.A. Somorjai, H. Heinemann, J.F. Garcia de la Banda, M. Lopez Granados, J.C. Conesa, J. Phys. Chem. 95 (1991) 240.

[47] G. Meunier, B. Mocaer, S. Kasztelan, L.R. LeCoustumer, J. Grimblot, J.P. Bonnelle, Appl. Catal. 21 (1986) 520.

[48] C.J. Brinker, R. Kirkpatrick, D.R. Tallant, B.C. Bunker, B. Montez, J. Non-Cryst. Solids 99 (1988) 418.

[49] (a) D.R. Tallant, B.C. Bunker, C.J. Brinker, C.A. Balfe, Mater. Res. Soc. Symp. Proc. 73 (1986) 261; (b) R.H. Stolen, G.E. Walrafen, J. Chem. Phys. 64 (1976) 2623; (c) B.C. Brinker, D.R. Tallant, E.P. Roth, C.S. Ashley, Mater. Res. Soc. Symp. Proc. 61 (1986) 387.

[50] D. Lin-Vien, N.B. Colthup, W.G. Fateley, J.G. Grasselli, The Handbook of Infrared and Raman Characteristic Frequencies of Organic Molecules, Academic Press, Boston, 1991.

[51] H. Okabayashi, K. Taga, K. Miyagai, T. Uehara, T. Yoshida, E. Nishio, J. Phys. Chem. 95 (1991) 7932.

[52] F.D. Hardcastle, I.E. Wachs, J. Phys. Chem. 95 (1991) 5031.

[53] (a) L. Abello, E. Husson, Y. Repelin, G. Lucazeau, J. Solid State Chem. 56 (1985) 379; (b) Y. Repelin, E. Husson, L. Abello, G. Lucazeau, Spectrochem. Acta 41A (1985) 993.

[54] I. Shimizu, H. Okabayashi, K. Taga, A. Yoshino, E. Nishio, C.J. O'Connor, Vibr. Spectrosc. 14 (1997) 125.

[55] D.H. Williams, I. Fleming, Spectroscopic Methods in Organic Chemistry, McGraw-Hill, Maidenhead, 1989, and references therein.

[56] This interpretation of the Raman results is supported by ${ }^{29} \mathrm{Si}$ CPMAS NMR experiments performed by Ulla Gro Nielson. C. Hess et al. / Microporous and Mesoporous Materials 95 (2006) 339-349 349 